Article

\title{
Functional Coupling Degree and Human Activity Intensity of Production-Living-Ecological Space in Underdeveloped Regions in China: Case Study of Guizhou Province
}

\author{
Xuesong Zhang ${ }^{1,2}$ and Zijin $\mathrm{Xu}{ }^{1,2,3, *}$ \\ 1 Key Laboratory of Geographical Process Analysis and Simulation, Central China Normal University, \\ Wuhan 430079, China; zhangxuesong@mail.ccnu.edu.cn \\ 2 The College of Urban and Environmental Sciences, Central China Normal University, Wuhan 430079, China \\ 3 Graduate School, Guizhou University of Finance and Economics, Guiyang 550025, China \\ * Correspondence: china-99@mail.gufe.edu.cn
}

check for

updates

Citation: Zhang, X.; Xu, Z.

Functional Coupling Degree and

Human Activity Intensity of

Production-Living-Ecological Space in Underdeveloped Regions in China: Case Study of Guizhou Province. Land 2021, 10, 56. https://doi.org/ 10.3390/land10010056

Received: 8 December 2020

Accepted: 6 January 2021

Published: 10 January 2021

Publisher's Note: MDPI stays neutral with regard to jurisdictional clai$\mathrm{ms}$ in published maps and institutional affiliations.

Copyright: $\odot 2021$ by the authors. Licensee MDPI, Basel, Switzerland. This article is an open access article distributed under the terms and conditions of the Creative Commons Attribution (CC BY) license (https:// creativecommons.org/licenses/by/ $4.0 /)$.

\begin{abstract}
Background: Clarify the coordinated development level of production, living, and ecological spaces in the underdeveloped areas of China and their relationship with the intensity of human activity. Explore and address the problems that are likely to be faced when developing these areas and improve the quality of China's new urbanization development. Promote the coordinated and sustainable development of the economy, society and ecology in underdeveloped areas. Guizhou Province is located in southwest China; the landform is broken and complex. Its economic development level is low. It is one of the representatives of underdeveloped areas in China. Therefore, Guizhou Province of China was selected as the study area. (2) Methods: This paper constructs the evaluation index system of the production-living-ecological space (PLES) functional system in China's underdeveloped areas, and uses the coupling coordination degree model to measure the development coordination level of the study area. The human activity intensity model was used to calculate the human activity intensity in the study area. Response index is introduced to analyze the relationship between the spatial function coupling coordination degree and the intensity of human activities. (3) Results: Before 2015, the level of functional coupling coordination degree of production-living-ecological space (PLES) in the study area fluctuated, and after 2015, it showed a stable and coordinated development trend. The intensity of human activity continues to increase, and the interaction between human activity and local production-living-ecological space (PLES) function coupling coordination is intense. (4) Conclusions: human activity is a significant factor affecting regional, coordinated and sustainable development. In less developed areas, the impact of human activity is more obvious. Human activity, in combination with the theory of the humanland relationship and the moderate intensity of human activity, are important ways to improve the coordinated and sustainable development of underdeveloped regions.
\end{abstract}

Keywords: production-living-ecological space (PLES); coupling coordination degree; human activity intensity; Guizhou Province; China

\section{Introduction}

Promoting coordinated regional development is not only a strategic goal but also the way forward and a driving force for the sustainable development of the national economy and society. The production-living-ecological space (PLES) function can be divided into production, living, and ecological spaces from the perspective of the multifunctionality aspect of the national territory. This space reflects the comprehensiveness, complexity, and systematicity of the national territorial space. This concept exerts an important influence on the coordinated development of regions. In China, the existing studies on production-living-ecological space (PLES) focus mainly on the definition and connotation 
of the concept, evolution of the space-time pattern, classification and function evaluation, coupling-coordination research, and relevant studies on the subspaces within the production-living-ecological space function. Huang Jinchuan et al. [1] proposed a detailed definition of the concept and connotation of production-living-ecological space. Chen Qianqian et al. [2] performed a multiscale analysis of the spatial and temporal patterns of the production-living-ecological space structure of Jiangxi Province. Gao Xing et al. [3] studied the land-use function transformation and ecological environment effects of the Xiongan New Area based on the production-living-ecological space. Liu Pengfei et al. [4] analyzed the pattern and related factors of the quality of urban production, living, and ecological spaces in China. Cheng et al. [5-7] performed studies on the spatio-temporal characteristics and pattern evolution of the coupling coordination of the rural productionliving-ecological space functions in Chongqing, as well as on the ordering and adaptability evaluation of the production space subsystem of the production-living-ecological space. Other countries have focused on the development and application of spatial planning in the study of the production-living-ecological space and have applied the latest theories of spatial zoning to guide city and town planners. European Union and developed countries such as Japan have performed several rounds of space planning [8,9]. To promote the implementation of space planning, Germany has constantly created related theories. The spatial planning of the Netherlands considers regional characteristics such as the development of remote areas, employment, and industrial agglomeration [10,11]. A review of the relevant literature indicates that the studies to date have focused on production-living-ecological spaces. However, it is necessary to broaden our understanding of this concept. At present, studies on production-living-ecological space focus on the land-use identification, landspace planning, and space subsystems based on current needs. In terms of the function evaluation of the production-living-ecological space, most of the studies in China focus only on scattered individual cities and cities in developed regions. Only a few studies have focused on the function evaluation of the production-living-ecological space in the western regions of the country. Particularly, no comprehensive research on the interaction and coordinated development of the production space, living space, ecological space function, and human activity intensity in western underdeveloped regions is available. Therefore, this study attempts to make the following contributions to the existing literature on production-living-ecological space.

First, this study uses the midpoint elasticity formula of economics as a reference and introduces the "response index" to quantitatively express the impact of the functional coordination-coupling degree of the production-living-ecological space on the intensity of human activities.

Next, at present, the research on the relationship between the production-livingecological space and human activity intensity in the underdeveloped areas of China is insufficient. In this study, Guizhou Province, an underdeveloped area in Western China, was selected as the study area to establish an evaluation index system for the productionliving-ecological space function level considering the local ground reality. Combined with the availability and authenticity of research data, the production space, living space, and ecological space function levels of the study area from 2012 to 2018 were comprehensively evaluated. The coupling-coordination degree model was used to measure the development coordination level of the study area, and the analysis was combined with the intensity of local human activities to reveal the spatio-temporal evolution of the land spatial function and the differentiation law of the intensity of local human activities in the underdeveloped areas of China. This study provides theoretical support and a practical basis for coordinated and sustainable regional development.

The main objectives of this study were as follows: (1) clarify the coordinated development level of production, living, and ecological spaces in the underdeveloped areas of China and their relationship with the intensity of human activities; (2) explore and address the problems likely to be faced in developing these areas; (3) improve the quality of China's 
new urbanization development and promote the coordinated and sustainable development of the economy, society, and ecology in the underdeveloped areas.

The specific contributions of this study include the following: (1) An evaluation index for the production-living-ecological space function suitable for the study area is constructed. (2) The proposed evaluation index is used to obtain the spatial function level of the production-living-ecological space in the study area based on local statistical data. (3) A mature model is used to calculate the intensity of human activity in the study area. (4) The relationship between the spatial function pairs, coordination degree of the production-living-ecological spaces, and intensity of human activity in the study area is explored. (5) A case study is conducted on the relationship between the spatial function coupling-coordination level and human activities in the underdeveloped areas in China; this case study is expected to be helpful to policy makers.

The remainder of this paper is organized as follows. Section 2 presents the materials and methods employed in this study. It also discusses the backdrop, study area and data sources relevant to this study. Section 3 presents the calculation results. Section 4 presents the conclusion and final discussion.

\section{Materials and Methods}

\subsection{Study Area and Data}

The economic development level of Guizhou Province is low. It is one of the representatives of underdeveloped areas in China. Therefore, Guizhou Province of China is selected as the study area.

Guizhou Province is located in the southeast of Southwest China, bounded by Hunan in the east, Guangxi in the south, Yunnan in the west, and Sichuan and Chongqing in the north. The total land area of the province is $176,100 \mathrm{~km}^{2}$, accounting for $1.8 \%$ of the national land area. There are 9 cities in Guizhou province (Figure 1) [12]. The altitude of the province is higher in the west and lower in the east (Figure 2). Based on the preliminary calculation of the National Bureau of Statistics, the GDP of the province was expected to reach 1,676,934 billion yuan in 2019, an increase of $8.3 \%$ over the preceding year. At the end of 2019, the permanent resident population of the province was 362,295 million, an increase of 2,295,000 compared with the figure at the end of preceding year [13].

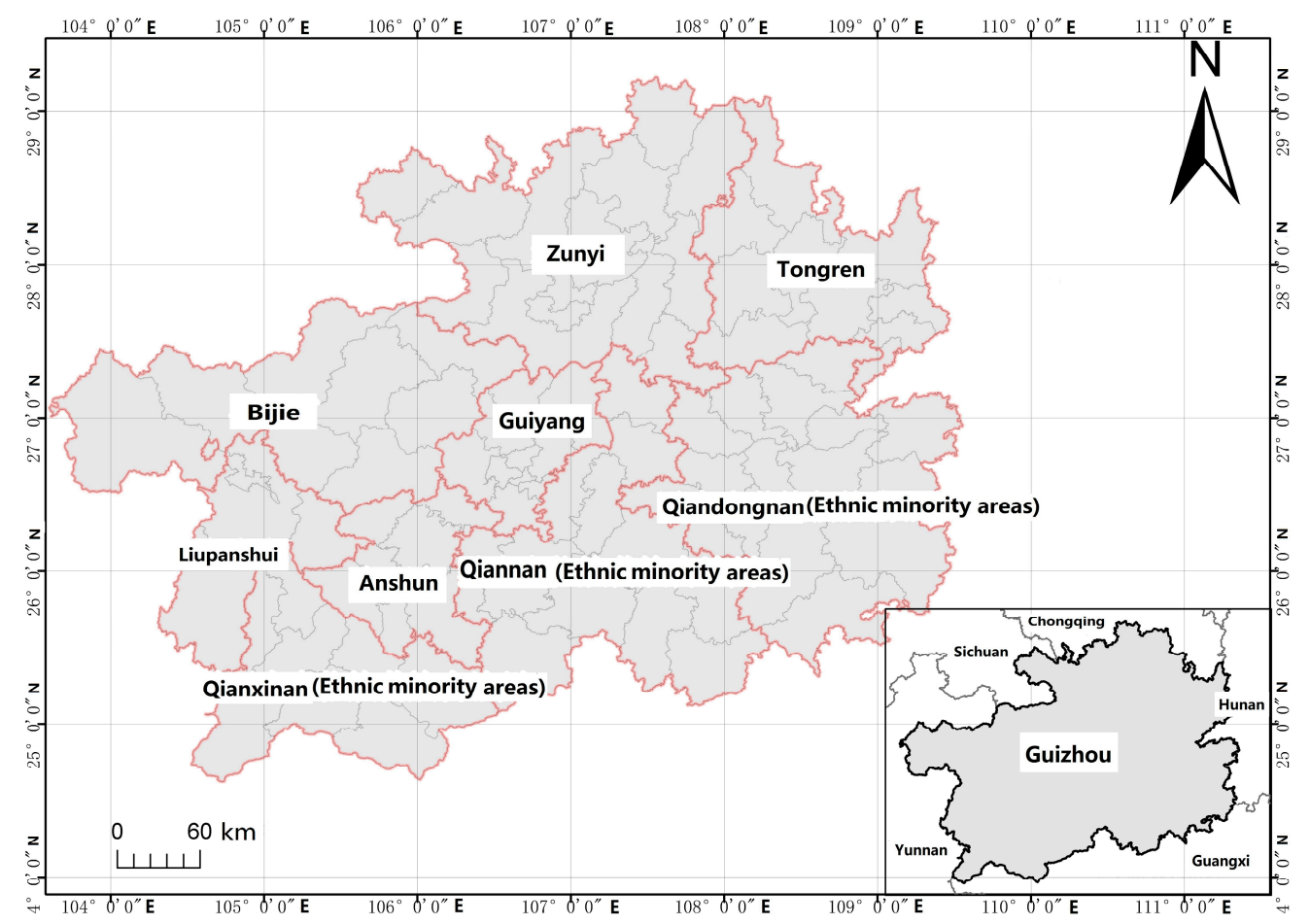

Figure 1. Location of study area. 


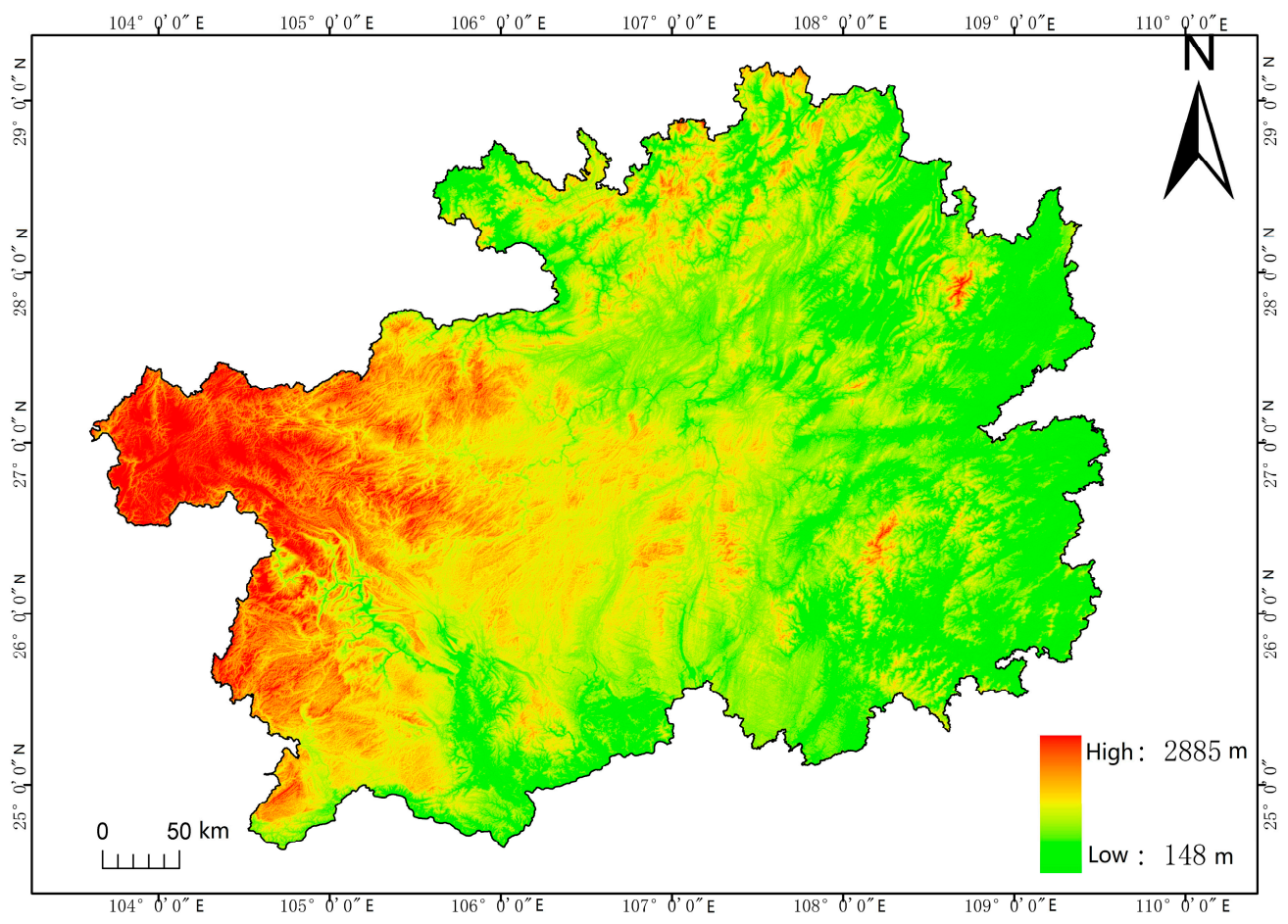

Figure 2. Elevation map of study area.

Based on the land-use change data of Guizhou Province for 2018, the agricultural, garden, forest, and grassland areas in Guizhou Province accounted for $27.37 \%, 0.99 \%$, $47.32 \%$, and $9.57 \%$, respectively, of the total area. The area of land under transport networks accounted for $1.15 \%$. Water and water conservancy areas accounted for $1.48 \%$. The area of unused land accounted for $8.66 \%$ (Table 1 ).

Table 1. Land-use data of study area.

\begin{tabular}{cc}
\hline Land-Use Type & Proportion of the Total Area \\
\hline Agriculture & $27.37 \%$ \\
Gardens & $0.99 \%$ \\
Forests & $47.32 \%$ \\
Grasslands & $9.57 \%$ \\
Residential, industrial, and mining & $3.46 \%$ \\
Transportation & $1.15 \%$ \\
Water and water conservancy facilities & $1.48 \%$ \\
Unused land & $8.66 \%$ \\
\hline
\end{tabular}

There are several mountains and hills, few flat lands in the dam area, and a wide distribution of karsts in this province. The characteristics of these land resources are as follows: (1) the distribution of land resources is three-dimensional; (2) the distribution of the vertical belt is wide, and the natural slope is large; (3) the natural slope of the cultivated land is mostly between $15^{\circ}$ and $25^{\circ}$; and (4) land types are fragmented and complex.

Owing to the inconsistent statistical caliber of economic and social data before 2012 in Guizhou Province, the data obtained before and after 2012 are not comparable. The economic and social data of 2019 have not been released officially. Therefore, we used the data pertaining to years 2012-2018. The economic and social data used in the study were sourced from China County Statistical Yearbook (county and city volume), Guizhou Statistical Yearbook, National Economic and Social Development Bulletin of Guizhou Province, and yearbooks of all prefectures and cities in Guizhou Province. Environmental pollution data were obtained from the website of the Guizhou Provincial Bureau of Statistics. Wherever some data were missing, we used the average growth difference between years 
2012 and 2018. The spatial data of the study area were sourced from the cloud platform of the geographic condition detection.

\subsection{Method}

Based on the existing literature and ground reality in the study area, this study constructs a function-evaluation index system for the production-living-ecological space in underdeveloped areas. All the data were standardized, and the entropy weight method was used to determine the weight of each parameter. The functional system levels and couplingcoordination degrees of the production-living-ecological space in Guizhou Province were calculated and compared based on data from 2012 to 2018. Furthermore, we calculated the intensity of human activities in Guizhou Province for these years and used the response index to perform a scientific analysis of the correlation between the two. The specific calculation method used in this study is described in the following section.

\subsubsection{Data Standardization}

Data on production-living-ecological space function evaluation span economic, social, spatial, ecological, and other domains. To make these data types comparable, it is necessary to eliminate their dimensional characters. Therefore, the data used in this study were first standardized using a range. The calculation formulas for this standardization are as follows.

Positive indicators:

$$
U_{i}=\frac{X_{i}-\min \left(X_{i}\right)}{\max \left(X_{i}\right)-\min \left(X_{i}\right)}
$$

Negative index:

$$
U_{i}=\frac{\max \left(X_{i}\right)-X_{i}}{\max \left(X_{i}\right)-\min \left(X_{i}\right)}
$$

where $U_{i}$ is the standardized data value, $X_{i}$ is the original data to be calculated in index $i$, $\min \left(X_{i}\right)$ is the minimum value of the original data in index $i$, and $\max \left(X_{i}\right)$ is the maximum value of the original data in index $i$.

\subsubsection{Entropy Weight Method}

The entropy weight method is used to measure the uncertainty in a variable with the overall concept. This method eliminates any uncertainty in the evaluation and analysis to the maximum extent and makes the evaluation objective [14]. In this study, the weight of each parameter in the production-living-ecological space function evaluation index was determined using an algorithm. The calculation formula is as follows.

Specific gravity calculation:

$$
R_{i}=\frac{X_{i}}{\sum_{i=1}^{n} X_{i}}
$$

Entropy calculation:

$$
e_{i}=-k \sum_{i=1}^{n} R_{i} \ln \left(R_{i}\right)
$$

Weight calculation:

$$
W_{i}=\frac{1-e_{i}}{\sum_{i=1}^{n}\left(1-e_{i}\right)}
$$

where $R_{i}$ is the normalized value of the original data, $X_{i}$ is the original data, and maxei is the maximum value. 


\subsubsection{Production-Living-Ecological Space Function-Evaluation Model}

The comprehensive development level of the production-living-ecological space system in the study area was evaluated using a production-living-ecological space functionevaluation model [15]. The calculation formula is as follows

$$
Q_{k}=\sum_{i=1}^{n} U_{i} W_{i}
$$

where $Q_{k}$ is the function-evaluation value of subsystem $k$, with $k=1,2$, and 3 representing the production, living, and ecological space subsystems.

\subsubsection{Production-Living-Ecological Space Function-Evaluation Index System}

The production-living-ecological space function-evaluation index system is a comprehensive composite system. It is composed of production, living, and ecological space function subsystems. By referring to the existing research results, considering the authenticity and accessibility of the research data, and combined with the ground reality in the study area, this study proposed a function-evaluation index system for the productionliving-ecological space in Guizhou Province (Table 2). The weight of the index layer was determined using the entropy weight method.

Because the contribution of each subsystem to the regional sustainable development cannot be calculated quantitatively, each subsystem was given a weight ranging from 1 to 3 based the importance of the subsystem [16].

Table 2. Function-evaluation index system for production-living-ecological space.

\begin{tabular}{|c|c|c|c|}
\hline Target Layer & Rule Layer & Index Layer & Index Property \\
\hline \multirow{5}{*}{$\begin{array}{c}\text { Function of } \\
\text { production space }\end{array}$} & \multirow{4}{*}{ Level of economic development } & Per capita GDP (yuan) & Positive \\
\hline & & GDP growth rate $(\%)$ & Positive \\
\hline & & Growth rate of fixed asset investment (\%) & Positive \\
\hline & & Per capita disposable income (yuan) & Positive \\
\hline & Proportion of productive land & Production area/Total land area (\%) & Positive \\
\hline \multirow{5}{*}{$\begin{array}{l}\text { Function of } \\
\text { living space }\end{array}$} & Traffic & Road network density $\left(\mathrm{km} / \mathrm{km}^{2}\right)$ & Positive \\
\hline & Education condition & $\begin{array}{l}\text { Number of full-time teachers per capita } \\
\text { (teachers } / 10,000 \text { persons) }\end{array}$ & Positive \\
\hline & Sanitary conditions & $\begin{array}{c}\text { Number of beds per capita in health institutions } \\
\text { (beds/thousand) }\end{array}$ & Positive \\
\hline & Living quality & Population density (persons $/ \mathrm{km}^{2}$ ) & Negative \\
\hline & Proportion of living land & Living area/total land area $(\%)$ & Positive \\
\hline \multirow{6}{*}{$\begin{array}{c}\text { Function of } \\
\text { ecological space }\end{array}$} & \multirow{3}{*}{ Environmental pollution } & Sulfur dioxide emissions (tons $/ 10,000$ people) & Negative \\
\hline & & Wastewater discharge per capita (tons) & Negative \\
\hline & & $\begin{array}{c}\text { Comprehensive utilization rate of industrial } \\
\text { solid waste }(\%)\end{array}$ & Positive \\
\hline & \multirow{2}{*}{ Environmental governance } & Per capita public green space $\left(\mathrm{m}^{2} /\right.$ person $)$ & Positive \\
\hline & & Harmless disposal rate of household garbage (\%) & Positive \\
\hline & Proportion of ecological land & Ecological area/Total land area $(\%)$ & Positive \\
\hline
\end{tabular}

\subsubsection{Coupling-Coordination Model}

We borrowed a concept, called the degree of coupling coordination, from physics. This concept describes the degree of the interaction between two or more systems. The degree of coupling and coordination determines the development of a system [17]. The calculation formula is as follows

$$
C=\left[\left(Q_{1} Q_{2} Q_{3}\right) /\left(\frac{Q_{1}+Q_{2}+Q_{3}}{3}\right)^{3}\right]^{\frac{1}{3}}
$$


where $C$ is the coupling degree of the system, and its value is between 0 and 1 . The closer the $C$ value to 1 , the higher the coupling degree of the three subsystems of the system. However, the coupling degree can only explain the strength and correlation of the interaction among the subsystems in the production-living-ecological space system [18]. This cannot reflect the level of coordinated development within the overall system. Therefore, a couplingcoordination degree model was introduced to analyze the coordination degree of the interaction coupling among the three subsystems in the production-living-ecological space system in the study area. The model is as follows

$$
D=\sqrt{C \cdot\left[\left(Q_{1} Q_{2} Q_{3}\right) / 3\right]}
$$

where the higher the $D$ value, the higher the coupling coordination degree.

\subsubsection{Calculation Model of Human Activity Intensity}

The intensity of human activities is a comprehensive indicator of the impact of human activities on the land [19]

$$
\begin{gathered}
\text { HAILS }=\frac{S_{C L E}}{S} \times 100 \% \\
S_{C L E}=\sum_{i=1}^{n}\left(S L_{i} \cdot C I_{i}\right)
\end{gathered}
$$

where HAILS is the intensity of human activities on the surface of the land, $S_{C L E}$ is the equivalent area of construction land, $S$ is the total area of the study area, $S_{L i}$ is the area of type-I land use/cover, and $C_{I i}$ is the equivalent conversion coefficient of the construction land of type-I land use/cover, and $n$ is the number of land-use/cover types in the region.

Construction land equivalent (CLE) refers to a unit of measurement used to compare the effects of various human activities on the land surface and is reflected by the landuse/cover types [20]. Referring to the existing literature [21,22], the equivalent conversion coefficients of construction land $\left(\mathrm{C}_{\mathrm{I}}\right)$ [23] for various land-use types are listed in Table 3.

Table 3. Equivalent conversion coefficients of construction land for various land-use types.

\begin{tabular}{cc}
\hline Land-Use Type & CI \\
\hline Cultivated land & 0.2 \\
Garden & 0.19 \\
Forest & 0.13 \\
Grassland & 0.1 \\
Residential and industrial/mining & 1 \\
Transport & 1 \\
Water and water conservancy facilities & 0.6 \\
Unused & 0 \\
\hline
\end{tabular}

\subsubsection{Response Model of Production-Living-Ecological Space Function} Coupling-Coordination Degree to Human Activity Intensity

Correlation analysis is the statistical analysis of two or more variables to measure the closeness between the variables [24]. To quantitatively evaluate the response of the functional coordination-coupling degree of the production-living-ecological space to the intensity of human activities, this study used the midpoint elasticity formula of economics for reference and introduced a "response index" to express the response degree of the functional coordination-coupling degree of the production-living-ecological space to the intensity of human activities. The calculation formula is as follows

$$
R=\frac{d_{D}}{d_{H A I L S}} \cdot \frac{H A I L S}{D}
$$

where $d_{D}$ is the derivative of the function coupling-coordination degree of the productionliving-ecological space, and $d_{\text {HAILS }}$ is the derivative of the human activity intensity. 


\section{Calculation Results}

\subsection{Results of Coupling-Coordination Degree of Production-Living-Ecological Space System}

Based on the value of the coupling-coordination degree of the production-livingecological space functional system of each municipal administrative district in the study area, the coupling-coordination degrees of the production-living-ecological space system functional systems in the nine municipal administrative regions of the study area, from 2012 to 2018, were desirable. The coupling-coordination degree in Qiandongnan Prefecture indicated significant fluctuation. The coupling-coordination degree in Qianxinan Prefecture was low in 2013. The coupling-coordination degrees in Guiyang and Tongren decreased slightly from 2012 to 2018 and recovered thereafter. The coupling-coordination degree in Zunyi decreased significantly from 2017 to 2018. The coupling-coordination degrees in other cities and prefectures increased steadily from 2012 to 2018. In 2016, the couplingcoordination degree in the Guiyang city crossed 0.5. In 2015, the coupling-coordination degrees in the Zunyi and Anshun cities crossed 0.5. In 2014, the coupling-coordination degrees in Tongren, Bijie, Liupanshui, Qiannan, and Qianxinan crossed 0.5. In 2014, the coupling-coordination degree in Qiandongnan Prefecture crossed 0.5. The couplingcoordination degree in Qiandongnan Prefecture crossed 0.520 in 2014, reached its peak in 2015, then decreased, and again increased steadily from 2016 (Figure 3).

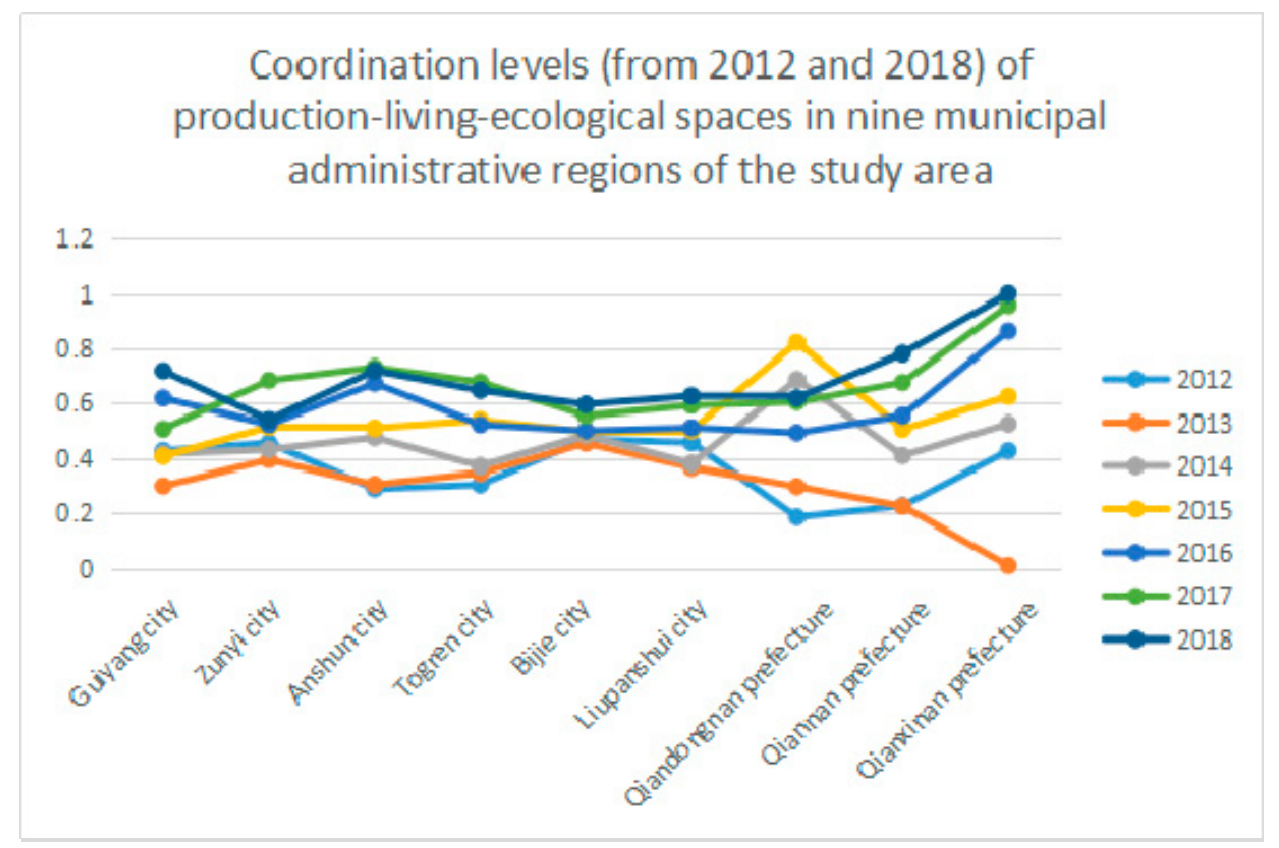

Figure 3. Coordination levels (from 2012 and 2018) of production-living-ecological spaces in nine municipal administrative regions of the study area.

From 2012 to 2018, the policy guidelines of the local government in Guizhou promoted the coordinated development of the local production-living-ecological space functional system. Among these, the balance between the production (economic development) and ecological space functions (ecological protection) was both the difficulty in and key to improving the efforts for sustainable development. Striking a balance between the two competing objectives caused fluctuations between the level of regional economic development and level of ecological protection.

\subsection{Results of Human Activity Intensity}

From 2012 to 2018, the results indicate that Guiyang and Zunyi exhibited higher human activity intensities in the entire province. The intensities of human activities in the Bijie city, Qiandongnan Prefecture, Qiannan Prefecture, and Qianxinan Prefecture were weak. 
Although the intensity of human activities in the study area fluctuated slightly over the years, it continued to strengthen, as is reflected in the economic development of Guizhou. The minority areas show a moderate correlation, which indicates that these areas have their own characteristics.

3.3. Results of Functional Coupling-Coordination Degree of Production-Living-Ecological Space in Response to the Intensity of Human Activities

If response index $R$ is positive, it indicates that there is a positive response relationship between the intensity of human activities and the function coupling coordination degree of the production-living-ecological space, and the intensity of human activities has a positive impact on the function coupling coordination in the production-living-ecological space. When $R$ is negative, it indicates that there is a negative response relationship between the intensity of human activities and the function coupling coordination degree of the production-living-ecological space, and the intensity of human activities has a negative impact on the function coupling coordination degree of the production-living-ecological space. When $R$ is 0 , it means that there is no theoretical relationship between the intensity of human activities and the function coupling coordination degree of the production-livingecological space.

The results indicate that, before 2017, there is no obvious trend in the response degree of the production-living-ecological space function coupling coordination degree to human activity intensity, and the relationship between them is disordered. While the intensity of human activity is threatening production, life and ecological spaces, there are also constraints on the intensity of human activity in terms of production, life and ecological spaces. The negative response of Qiandongnan Prefecture in 2013 and 2014 indicates that the development of the human-land relationship was not coordinated, and the contradiction between human activity intensity and the production-life-ecological space system is evident. In 2016, Bijie City and Qiandongnan Prefecture showed a significant degree of negative response, which indicates that this contradiction was severe in these areas. From 2017 to 2018, the response degree of the production-living-ecological space function coupling coordination degree to human activities tended to be stable (Figure 4).

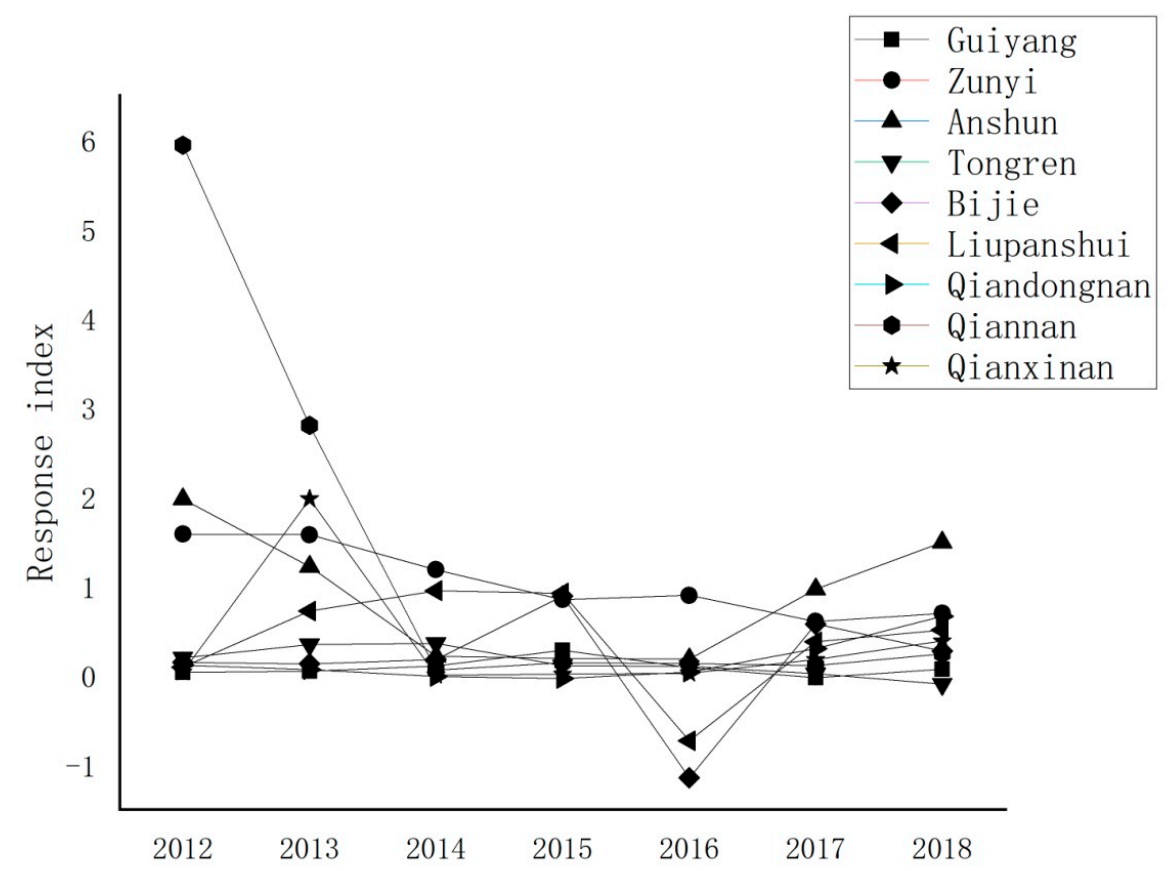

Figure 4. Response indices of production-living-ecological space function coupling coordination degrees to human activity intensities in various parts of the study area. 
From 2012 to 2018, the coupling coordination degree of the production-living-ecological space functional system and the intensity of human activities in the study area tended to be stable in the fierce interaction. Before 2016, the rapid and strong economic and social development of Guizhou Province brought serious conflict between humans and land use. However, the local government constantly adjusted the development ideas. Learning the experiences of economic and social development in economically developed areas, the government initiated steps to conform to the actual development method of the study area, effectively alleviating the conflict between people and land use.

Based on the actual situation in the underdeveloped areas in Guizhou Province, policies were formulated incrementally to promote sustainable development. The administration vigorously supported big data, tourism, and other industries suitable for the development of Guizhou, and closed many enterprises that contributed to serious ecological pollution. The local administration in Guizhou Province actively engaged in the prevention and control of karst rocky desertification, gave priority to environmental protection, and strove to protect the ecological environment of the province. In doing so, fluctuations occurred in the coupling-coordination degree of the production-livingecological space function system of the nine prefectures and cities in the study. This is the data embodiment of the game between regional production space function (mainly reflected in economic development) and ecological space function (mainly reflected in ecological protection). After 2014, the coupling-coordination degree in the study area indicated an overall positive trend. This degree reached crossed 0.5 in 2015, which indicates that the production-living-ecological space functional system of the study area was continuously optimized, and the sustainable development ability of the production-living ecological space was continuously enhanced. The intensity of human activities in the study area continued to increase on the whole, and the degree of coupling coordination with the function of production-living-ecological space in the study area gradually stabilized in the process of intense interaction.

\section{Discussion}

Exploring the spatial function coupling-coordination level of the production-livingecological space in underdeveloped areas is a quantitative study of imbalances in the regional development. It is a novel way to explore the relationship between the couplingcoordination level of the major land functions and the intensity of human activity [25-27]. As a mixed system of society, economy, culture, and ecology, the production-livingecological space needs all agents to achieve mutual coupling and coordination. Human beings, as the principal agent capable of active transformation, have an obvious impact on the functional system of the production-living-ecological space.

Based on the theoretical and empirical evidence available in the literature, this study is the first to explore the relationship between the production-living-ecological space function coupling-coordination level and the intensity of human activity in underdeveloped areas in China. Based on the entropy weight method, the evaluation index of the productionliving-ecological space function system in developed areas of China is constructed. The concept of coupling degree is introduced to calculate the coupling-coordination level of the production-living-ecological space in the study area. We used the human activity intensity model to understand the level of human activities in the study area. We took recourse to the elastic formula in economics, and introduced the response index to analyze the relationship between the production-living-ecological space function coupling-coordination degree and human activity intensity in the study area. The findings of this study complement the literature and methods of the spatial function system of the production-living-ecological space and the intensity of human activities in underdeveloped areas.

\section{Conclusions}

The results of this study suggest that a high coupling-coordination degree among the functional production, living, and ecological spaces in underdeveloped areas is indicative 
of the sustainable regional development. Because humans are the only agent capable of objective transformation, their activities have the most direct impact on the function of the production-living-ecological space [28-30]. To a certain extent, human activities can determine the coupling degree of the spatial function coordination of the productionliving-ecological space, thereby affecting the level of regional sustainable development. Therefore, in the process of regional development, we must adjust development measures to local conditions. In the areas with high levels of economic development, we should appropriately control the intensity of human activity to ensure a coordinated operation of the production-living-ecological space functional system before enhancing the level of sustainable development in economically developed areas. In areas with low levels of economic development, we should moderately enhance the intensity of human activity, promote the coordinated operation of the production-living-ecological space function system, reduce the imbalance and insufficiency in regional development, and improve the level of regional sustainable development. Our findings lead us to the following key conclusions.

First of all, human activity is a significant factor affecting regional coordinated and sustainable development. In less developed areas, the impact of human activity is more obvious. A healthy and orderly development is needed to ensure the sustainable development of underdeveloped areas to ensure balanced development among regions. As an agent with the objective ability to transform, human beings have a significant impact on the regional sustainable development. This ability has both positive and negative effects. The positive effect is that well-thought-out human activities can promote the orderly development of the production-living-ecological space function. In contrast, random and thoughtless human activities can seriously affect both the orderly development of this space and the coordinated and sustainable development of a region. For example, afforestation activities in China have enhanced the positive function of the ecological space, improved air quality, and protected biodiversity. The unchecked construction activities on farm, forest, and grass lands accelerate the fragmentation of ecological space, lead to a decline in biodiversity, destroy the balance of the ecosystem, and weaken the function of ecological space services.

Second, human activity, in combination with the theory of the human-land relationship and the moderate intensity of human activity, are important ways to improve the coordinated and sustainable development of underdeveloped regions. To a certain extent, the abnormally high intensity of human activity is the root cause of the lack of regional coordinated sustainable development. This not only leads to excessive consumption of material resources in the production-living ecological space, it also leads to the destruction of the structure of the functional system of this space and threatens the regional carrying capacity. This, in turn, leads to areas not being fully developed and living and ecological spaces being destroyed. The purpose of controlling and guiding the intensity of human activities is to improve production-living-ecological space function coupling and promote regional coordinated and sustainable development. We believe that the carrying capacity of the production-living-ecological space in underdeveloped areas must be the upper limit of human activities. When this limit is exceeded, the functional system of the productionliving-ecological space in underdeveloped areas will be damaged, and regional sustainable development will be threatened. To realize the full development of underdeveloped areas and balanced development among the regions, it is necessary to guide the content and mode of human activities to conform to the law of the human-land system and control the intensity of human activities within a certain threshold.

Third, the functions of production, living, and ecological spaces investigated in this study were not absolutely isolated, but infiltrated one another. The same type of space performance can have two types of space functions at the same time. For example, the urban green belt has both living and ecological space functions. When a certain form of spatial expression has two or more functions at the same time, this study delimits the spatial ownership by its main functions. The production-living-ecological space system is a comprehensive complex system, and the interaction of each space subsystem is also 
complex, which has both positive and negative influences. For simplicity, this study considered the production-living ecological space system as a whole, from the perspective of its function, to avoid internal contradictions among the production, living and ecological space subsystems.

Author Contributions: Conceptualization, methodology, software, validation, formal analysis, data curation, writing — original draft preparation, visualization, writing—editing: Z.X.; project administration, funding, review: X.Z.; and Z.X. All authors have read and agreed to the published version of the manuscript.

Funding: This research is supported by the National Natural Science Foundation of China (grant number 42071455) and the special scientific research project of Hubei Provincial Land Consolidation Bureau in 2019.

Institutional Review Board Statement: Not applicable.

Informed Consent Statement: Not applicable.

Data Availability Statement: Publicly available datasets were analyzed in this study. This data can be found here: http://stjj.guizhou.gov.cn/.

Conflicts of Interest: The authors declare no conflict of interest.

\section{References}

1. Huang, J.; Lin, H.; Qi, X. Research progress of production-living-ecological space oriented to the optimization of national space. Adv. Geogr. Sci. 2017, 36, 378-391.

2. $\quad$ Paris, T.M.; Keats, R.W. Charactering and Measuring Sustainable Development. Rev. Adv. 2003, 7, 17.

3. Gao, X.; Liu, Z.; Li, C. Land use Function Transformation and ecological environment effect in Xiongan New Area based on production-living-ecological space. Acta Ecol. Sin. 2020, 40, 1-10.

4. Liu, P.; Bindong, S. Analysis on the quality pattern and related factors of Urban production-living-ecological space in China. Geogr. Res. 2020, 39, 13-24.

5. Wang, C.; Tang, N. Spatio-temporal characteristics and pattern evolution of coupling and Coordination of rural productionliving-ecological space functions in Chongqing. Geogr. Res. 2018, 37, 1100-1114.

6. Wang, C.; Zhou, M.; Li, H. Based on the dissipative structure system entropy model of rural production space order. Geogr. Res. 2019, 38, 619-631.

7. Cheng, W.; Zhuo, Q.L.; Fan, R.R. Adaptability evaluation and Obstacle factor analysis of rural production space system in Jiangjin District, Chongqing city. Geogr. Stud. 2020, 39, 1609-1624.

8. Cai, Y.; Gu, L.; Li, J.; Pan, S. The evolution and enlightenment of Six comprehensive land development plans in Japan. China Land Sci. 2008, 6, 76-80.

9. Kariminejad, N.; Hosseinalizadeh, M.; Pourghasemi, H.R.; Bernatek-Jakiel, A.; Campetella, G.; Ownegh, M. Evaluation of factors affecting gully headcut location using summary statistics and the maximum entropy model: Golestan Province, NE Iran. Sci. Total Environ. 2019, 677, 281-298. [CrossRef]

10. Fan, J.; Zhou, K.; Sun, W.; Chen, D. The subject value and academic innovation of humanism-Economic Geography in ecological Civilization construction. Prog. Geogr. Sci. 2013, 32, 147-160.

11. Wei, H.; Gao, C. China's Regional Coordinated Development Trend and Policy Adjustment thinking. Henan Soc. Sci. 2012, 20, 107-108.

12. Statistics Bureau of Guizhou Province. Guizhou Statistical Yearbook 2019; China Statistical Press: Beijing, China, 2019; pp. 427-439.

13. Wang, Z.; Zhu, D.; Liyan, W. Comprehensive carrying Capacity Evaluation of Beijing-Tianjin-Hebei City Cluster under regional Coordination. J. Cap. Univ. Econ. Bus. 2018, 20, 73-81.

14. Ngai, L.R.; Pissarides, C.A. Structural Change in a Multisector Model of Growth. Am. Econ. Rev. 2007, 97, 429-443. [CrossRef]

15. Ou, H.; Dai, W.; Huang, W.; Huang, K.; Xu, Y. Research on the comprehensive carrying capacity of Cities in Fujian Province based on production-living-ecological space. Acta Ecol. Sin. 2020, 39, 71-79.

16. Willemen, L.; Hein, L.; Martinus, E.F. Space for people, plants, and livestock? Quantifying interactions among multiple landscape functions in a Dutch rural region. Ecol. Indic. Landsc. Assess. Sustain. Plan. 2010, 10, 62-73. [CrossRef]

17. Nelson, E.; Mendoza, G.; Regetz, J.; Polasky, S.; Tallis, H.; Cameron, D.R.; Chan, K.M.A.; Daily, G.C.; Goldstein, J.; Kareiva, P.M.; et al. Modeling multiple ecosystem services, biodiversity conservation, commodity production, and tradeoffs at landscape scales. Front. Ecol. Environ. 2009, 7, 4-11. [CrossRef]

18. Yong, X.; Xiaoyi, S.; Qing, T. Intensity of human activity on the surface of land: Concept, method and application. Geogr. J. 2015, $70,1068-1079$.

19. Xiaoren, X.; Yong, X. Analysis of temporal and spatial variation of human activity intensity in the Loess Plateau. Geogr. Res. 2017, $3,661-672$. 
20. Mauser, W.; Klepper, G.; Rice, M.; Schmalzbauer, B.S.; Hackmann, H.; Leemans, R.; Moore, H. Transdisciplinary global change research: The co-creation of knowledge for sustainability. Curr. Opin. Environ. Sustain. 2013, 5, 420-431. [CrossRef]

21. Wenjun, P. Response Mechanism and Tolerance of Land Ecological Environment to Human Activities in Karst Mountain Areas; Guizhou University: Guizhou, China, 2018.

22. Shi, D.; Shi, Y. Multidimensional Assessment of Food Provisioning Ecosystem Services Using Remote Sensing and Agricultural Statistics. Remote Sens. 2020, 12, 3955. [CrossRef]

23. Turkcan, A. The effects of different types of biodiesels and biodiesel-bioethanol-diesel blends on the cyclic variations and correlation coefficient. Fuel 2020, 261, 116453. [CrossRef]

24. Yang, Y.; Bao, W.; Li, Y.; Wang, Y.; Chen, Z. Land Use Transition and Its Eco-Environmental Effects in the Beijing-Tianjin-Hebei Urban Agglomeration: A Production-Living-Ecological Perspective. Land 2020, 9, 285. [CrossRef]

25. Wan, J.; Su, Y.; Zan, H.; Zhao, Y.; Zhang, L.; Zhang, S.; Dong, X.; Deng, W. Land Functions, Rural Space Governance, and Farmers' Environmental Perceptions: A Case Study from the Huanjiang Karst Mountain Area, China. Land 2020, 9, 134. [CrossRef]

26. Lv, T.; Wang, L. Coupling Coordinated Development and Exploring Its Influencing Factors in Nanchang, China: From the Perspectives of Land Urbanization and Population Urbanization. Land 2019, 8, 178. [CrossRef]

27. Wang, J.; Li, Y.; Wang, Q.; Cheong, K.C. Urban-Rural Construction Land Replacement for More Sustainable Land Use and Regional Development in China: Policies and Practices. Land 2019, 8, 171. [CrossRef]

28. Chen, Q.; Xie, H. Temporal-Spatial Differentiation and Optimization Analysis of Cultivated Land Green Utilization Efficiency in China. Land 2019, 8, 158. [CrossRef]

29. Gu, W.; Liu, H. Spatial Structure, Hierarchy and Formation Mechanisms of Scientific Collaboration Networks: Evidence of the Belt and Road Regions. Chin. Geogr. Sci. 2020, 30, 959-975. [CrossRef]

30. Chen, L.; Ye, W.; Huo, C.; James, K. Environmental Regulations, the Industrial Structure, and High-Quality Regional Economic Development: Evidence from China. Land 2020, 9, 517. [CrossRef] 